\title{
Peucedanum japonicum Thunb. ethanol extract suppresses RANKL-mediated osteoclastogenesis
}

\author{
JEONG-MI KIM ${ }^{1 *}$, MUNKHSOYOL ERKHEMBAATAR ${ }^{2,3 *}$, GUEM-SAN LEE $^{4}$, \\ JIN-HYUN LEE ${ }^{5}$, EUN-MI NOH ${ }^{1}$, MINOK LEE ${ }^{1}$, HYUN-KYUNG SONG $^{1}$, \\ CHOONG HUN LEE ${ }^{6}$, KANG-BEOM KWON ${ }^{1,5}$, MIN SEUK KIM ${ }^{3}$ and YOUNG-RAE LEE ${ }^{1,7,8}$
}

\begin{abstract}
${ }^{1}$ Department of Microbiology, Center for Metabolic Function Regulation, Wonkwang University School of Medicine, Iksan, North Jeolla 54538, Republic of Korea; ${ }^{2}$ Department of Physiology, School of Pharmacology and Bio-Medicine,

Mongolian National University of Medical Science, Ulaanbaatar 14210, Mongolia; ${ }^{3}$ Department of Oral Physiology, Institute of Biomaterial-Implant, College of Dentistry, Wonkwang University; Departments of ${ }^{4}$ Herbology and ${ }^{5}$ Korean Physiology, Wonkwang University School of Medicine; ${ }^{6}$ Microelectronics and Display, Next Generation Industrial Radiation Technology RIC, Center for PV Human Resource Development;

${ }^{7}$ Department of Oral Biochemistry, Institute of Biomaterial-Implant, College of Dentistry;

${ }^{8}$ Integrated Omics Institute, Wonkwang University, Iksan, North Jeolla 54538, Republic of Korea
\end{abstract}

Received July 18, 2016; Accepted March 3, 2017

DOI: $10.3892 / \mathrm{etm} .2017 .4480$

\begin{abstract}
The constituents of Peucedanum japonicum Thunb. (PJ) exhibit biological and pharmacological activities, including anti-obesity, anti-oxidant and anti-allergic activities. The aim of the present study was to examine in vitro effects of PJ in RANKL-induced signaling pathways, which determine osteoclast differentiation. PJ ethanol extract (PEE) exhibited anti-osteoporotic activity by disrupting the phospholipase $\mathrm{C}$ (PLC)-Ca $\mathrm{Ca}^{2+}$-c-Fos/cAMP response element-binding protein (CREB)-nuclear factor of activated $\mathrm{T}$ cells, cytoplasmic 1 (NFATc1) signaling pathway during osteoclastogenesis. Murine bone marrow-derived macrophages (BMMs) were cultured and used to determine the effects of PJ in the receptor activator of nuclear factor $\kappa \mathrm{B}$ ligand (RANKL)-mediated osteoclastogenesis. The effects of PEE in the RANKL-mediated signaling
\end{abstract}

Correspondence to: Professor Min Seuk Kim, Department of Oral Physiology, Institute of Biomaterial-Implant, College of Dentistry, Wonkwang University, 460 Iksan-daero, Iksan, North Jeolla 54538, Republic of Korea

E-mail: happy1487@wku.ac.kr

Professor Young-Rae Lee, Department of Oral Biochemistry, Institute of Biomaterial-Implant, College of Dentistry, Wonkwang University, 460 Iksan-daero, Iksan, North Jeolla 54538, Republic of Korea E-mail: mindyr@wku.ac.kr

*Contributed equally

Key words: Peucedanum japonicum Thunb., receptor activator of nuclear factor $\kappa \mathrm{B}$ ligand, osteoclastogenesis, intracellular $\mathrm{Ca}^{2+}$ mobilization, nuclear factor of activated $\mathrm{T}$ cells cytoplasmic 1 cascade were evaluated using a standard in vitro osteoclastogenesis system. PEE treatment of BMMs significantly reduced the number of RANKL-mediated tartrate resistant acid phosphatase (TRAP)-positive multinucleated cells $(\mathrm{P}<0.05$ for 5 and $10 \mu \mathrm{g} / \mathrm{ml} \mathrm{PEE}, \mathrm{P}<0.01$ for 25 and $50 \mu \mathrm{g} / \mathrm{ml} \mathrm{PEE})$, without cytotoxic effects. Furthermore, the expression of differentiation-related marker genes, including TRAP, Oscar, Cathepsin $\mathrm{K}$, dendrocyte expressed seven transmembrane protein, ATPase $\mathrm{H}^{+}$Transporting V0 Subunit D2 and NFATc1, were markedly suppressed. PEE induced a transient increase in free cytoplasmic $\mathrm{Ca}^{2+}\left(\left[\mathrm{Ca}^{2+}\right]_{\mathrm{i}}\right)$ mobilization via voltage-gated $\mathrm{Ca}^{2+}$ channels and PLC-sensitive pathways. Transient $\left[\mathrm{Ca}^{2+}\right]_{\mathrm{i}}$ increase consequently resulted in the suppression of c-Fos, CREB and NFATc1 activities. These findings highlight the potential use of PJ in treating bone disorders caused by osteoclast overgrowth.

\section{Introduction}

Peucedanum japonicum Thunb. (PJ), which belongs to the Umbelliferae family, has been widely used as traditional medicine and supplement used to produce food. In recent decades, studies have indicated that PJ may have antioxidant, anti-obesity and anti-spasmolytic properties (1-3). Notably, it was demonstrated that compounds isolated from PJ exert antagonistic effects on smooth muscle contraction by altering free cytoplasmic $\mathrm{Ca}^{2+}\left(\left[\mathrm{Ca}^{2+}\right]_{\mathrm{i}}\right)$ mobilization (3). Free $\mathrm{Ca}^{2+}$ ions are known to mediate a diverse range of cellular processes. In particular, the stimulation of receptor activator of nuclear factor- $\kappa \mathrm{B}$ ligand (RANKL) on bone marrow-derived macrophages (BMMs) elicits $\left[\mathrm{Ca}^{2+}\right]_{i}$ mobilization in the form of oscillation (4). RANKL-induced $\left[\mathrm{Ca}^{2+}\right]_{\mathrm{i}}$ oscillations sequentially activate $\mathrm{Ca}^{2+} /$ calmodulin-calcium/calmodulin-dependent protein kinase IV/calcineurin-c-fos/nuclear factor of activated $\mathrm{T}$ cells, cytoplasmic 1 (NGATc1) 
signaling, triggering the final stages of differentiation into osteoclasts (4-6).

During RANKL-mediated osteoclastogenesis, $\left[\mathrm{Ca}^{2+}\right]_{\mathrm{i}}$ is simultaneously mobilized from internal and external $\mathrm{Ca}^{2+}$ stores via numerous signaling pathways and the suppression of $\left[\mathrm{Ca}^{2+}{ }_{i}\right.$ oscillation by numerous factors disrupt downstream of $\left[\mathrm{Ca}^{2+}\right]_{i}$ oscillations (7-10). This can be disrupted by natural products, for example, a recent study by the current authors reported that the constituents of Glechoma hederacea elicited a transient increase in $\left[\mathrm{Ca}^{2+}\right]_{\mathrm{i}}$ and suppressed $\left[\mathrm{Ca}^{2+}\right]_{\mathrm{i}}$ oscillations by modulating voltage-gated calcium channels (VGCCs), thus inhibiting RANKL-mediated osteoclastogenesis (11). Furthermore, it was determined that (+)-cis-4'-O-acetly-3'-O-angeloylkhellactone, a bioactive compound isolated from $\mathrm{PJ}$, causes relaxation in isolated rat thoracic aorta by modulating VGCCs (12). These studies have indicated that PJ and its extracts exert potential effects on RANKL-mediated osteoclastogenesis and its underlying mechanisms. In the current study, it was demonstrated that PJ ethanol extract (PEE) alters RANKL-mediated signaling and expression of differentiation-related genes by modulating $\left[\mathrm{Ca}^{2+}\right]_{\mathrm{i}}$ responses, resulting in the suppression of TRAP-positive multinucleated cells (MNCs) formation.

\section{Materials and methods}

Experimental animals. All experiments were performed with BMMs isolated from the femur and tibia of C57BL/6J mice purchased from Orient Bio Inc. (Seongnam, Korea). Mice (C57BL/6 J) were housed, 4 animals per cage under specific pathogen-free conditions for 3 weeks (12/12 h light/dark cycles at a temperature of $22 \pm 2^{\circ} \mathrm{C}$ and $50-60 \%$ humidity). A total of 20 mice (male, 6-8 weeks old) weighing $20 \mathrm{~g}$ were sacrificed by brief exposure to $100 \% \mathrm{CO}_{2}$ and cervical dislocation for all subsequent experiments. All mouse studies were performed in accordance with protocols approved by the Animal Care and Use Committee of Wonkwang University (approval no. WKU16-4).

Reagents. PJ ethanol extract (95\%), which was prepared as described in 'Preparation of PJ extract', was used through all experiments in this study. All cell culture media, fetal bovine serum (FBS) and supplements were purchased from HyClone (GE Healthcare Life Sciences, Logan, UT, USA). Recombinant murine soluble RANKL and recombinant murine macrophage colony-stimulating factor (M-CSF) were purchased from PeproTech, Inc. (Rocky Hill, NJ, USA). Nicardipine and U73122, inhibitors of voltage-gated $\mathrm{Ca}^{2+}$ channel (VGCC) and phospholipase C respectively (PLC), were obtained from Sigma-Aldrich; Merck KGaA (Darmstadt, Germany). Antibodies against phospho-phospholipase C (PLC) $\gamma 2$ (no. 3874), cAMP response element-binding protein (CREB, no. 9197) and p-CREB (no. 9198) were purchased from Cell Signaling Technology, Inc. (Danvers, MA, USA). Anti-NFATc1 (no. sc7294), anti-PLC 22 (no. sc5238) and anti-c-fos (no. sc253) antibodies were purchased from Santa Cruz Biotechnology, Inc. (Dallas, TX, USA).

Preparation of PJ extract. The roots of PJ were purchased from a local herbal company (Kwangmyungdang Medicinal Herbs Co., Ltd., Ulsan, Korea) and authenticated by Professor
G.S. Lee. A voucher specimen (WKU010107-PJ201305E) was deposited at the Department of Herbology, College of Korean Medicine, Wonkwang University (Iksan, Korea). Dried PJ roots $(100 \mathrm{~g})$ were ground into fine powder and then extracted with $1,000 \mathrm{ml} 70 \%$ aqueous ethanol for $1 \mathrm{~h}$ using ultrasonic extractor (Powersonic 505; Hwashin Tech, Daegu, Korea). The extract was evaporated under $40 \mathrm{mmHg}$ using a rotary evaporator (N-1110S-W; Eyela, Tokyo, Japan) and lyophilized using freeze-dryer $\left(-50^{\circ} \mathrm{C}\right.$; ILShin BioBase, Co., Ltd., Dongducheon, Korea). The yield of the final extract was $12.02 \%$ (w/w).

Cell viability assay. Cell viability assays were performed using the EZ-Cytox Enhanced Cell Viability assay kit (Daeil Lab Service Co., Ltd., Seoul, Korea), according to the manufacturer's instructions. Briefly, BMMs, which act as osteoclast precursors, were plated in 96-well culture plates at a density of $1 \times 10^{4}$ cells/well with different concentrations of PEE $(0,2$, $5,10,25$ and $50 \mu \mathrm{g} / \mathrm{ml}$ ) for 1 day at $37^{\circ} \mathrm{C}$, or were treated with $25 \mu \mathrm{g} / \mathrm{ml}$ PEE under M-CSF treatment (30 $\mathrm{ng} / \mathrm{ml})$ for 4 days at $37^{\circ} \mathrm{C}$. All cells were incubated with $10 \mu \mathrm{l} \mathrm{EZ-Cytox} \mathrm{reagent}$ for $4 \mathrm{~h}$ at $37^{\circ} \mathrm{C}$. Following incubation, the optical density was measured using a microplate reader (Sunrise; Tecan Group Ltd., Männedorf, Switzerland) at $450 \mathrm{~nm}$.

In vitro osteoclast differentiation. Murine osteoclasts were prepared from bone marrow cells as previously described (13). Bone marrow cells were collected from the tibiae and femora of 6-8-week-old mice, following sacrifice (previously described in 'Experimental animals') by flushing the marrow space with phosphate-buffered saline (PBS) and were cultured at $37^{\circ} \mathrm{C}$ in the presence of M-CSF (30 ng/ml) for 3 days in $\alpha$-minimal essential medium ( $\alpha$-MEM) supplemented with 10\% FBS and 5\% antibiotics (Antibiotic-Antimycotic 100x; Gibco; Thermo Fisher Scientific, Inc., Waltham, MA, USA). Cells attached on Petri dish were replated on the desired cell culture dish and used as osteoclast precursors (bone marrow-derived macrophages, BMMs). To generate osteoclasts, BMMs were cultured with M-CSF (30 ng/ml) and RANKL (100 ng/ml) at $37^{\circ} \mathrm{C}$ for 4 days. Medium was replaced on day 3 with fresh $\alpha-M E M$ containing M-CSF and RANKL. Cells were fixed in $10 \%$ formalin at room temperature for $10 \mathrm{~min}$ and stained for tartrate resistant acid phosphatase (TRAP) activity. To measure total TRAP activity, p-nitro phenyl phosphate (Sigma-Aldrich; Merck KGaA) was used as a substrate of TRAP, and then optical density was measured at an absorbance of $405 \mathrm{~nm}$ using microplate reader. Following the measurement of total TRAP activity, TRAP positive-multinuclear cells (TRAP ${ }^{+} \mathrm{MNCs}$ ) containing $>3$ nuclei were counted using light microscope.

Reverse transcription-quantitative polymerase chain reaction $(R T-q P C R)$. BMMs treated with or without PEE were cultured with M-CSF (30 ng/ml) and RANKL (100 ng/ml) for 4 days as described above. Total RNA was extracted from cultured cells using TRIzol ${ }^{\circledR}$ reagent (Invitrogen; Thermo Fisher Scientific, Inc.) on days $0,1,2,3$ and 4 . Thereafter, $1 \mu \mathrm{g}$ total RNA was transcribed to first strand cDNA with random primers from the Maxima Reverse Transcriptase (Thermo Fisher Scientific Inc.) according to the manufacturer's protocol. qPCR was performed using the VeriQuest SYBR-Green qPCR Master mix (Affymetrix, Inc., Santa Clara, CA, USA) and the 
StepOnePlus Real-Time PCR system (Applied Biosystems; Thermo Fisher Scientific, Inc.). PCR was performed with a preliminary incubation at $95^{\circ} \mathrm{C}$ for $10 \mathrm{~min}$, followed by 40 cycles of $95^{\circ} \mathrm{C}$ for $15 \mathrm{sec}$ and $60^{\circ} \mathrm{C}$ for $1 \mathrm{~min}$. To control for variation in mRNA concentrations, all results were normalized to the GAPDH housekeeping gene. Relative quantitation was performed using the comparative $2^{-\Delta \Delta C q}$ method (14). The PCR primers used were as follows: Mouse TRAP, forward, 5'-CTGGAGTGCACGATGCCAGCGACA-3' and reverse, 5'-TCCGTGCTCGGCGATGGACCAGA-3'; Oscar, forward, 5'-GGGGTAACGGATCAGCTCCCCAGA-3' and reverse, 5'-CCAAGGAGCCAGAACGTCGAAACT-3'; Cathepsin K (CTSK) forward, 5'-ACGGAGGCATTGACTCTGAAG ATG-3' and reverse, 5'-GTTGTTCTTATTCCGAGCCAA GAG-3'; dendrocyte expressed seven transmembrane protein (TM7SF4), forward, 5'-TGGAAGTTCACTTGAAACTAC GTG-3' and reverse, 5'-CTCGGTTTCCCGTCAGCCTCT CTC-3'; ATPase $\mathrm{H}^{+}$Transporting V0 Subunit D2 (ATP6V0D2), forward, 5'-TCAGATCTCTTCAAGGCTGTGCTG-3' and reverse, 5'-GTGCCAAATGAGTTCAGAGTGATG-3'; NFATC1, forward, 5'-CTCGAAAGACAGCACTGGAGC AT-3' and reverse, 5'-CGGCTGCCTTCCGTCTCATAG-3'; and GAPDH, forward, 5'-TGCCAGCCTCGTCCCGTA GAC-3' and reverse, 5'-CCTCACCCCATTTGATGTTAG-3'. PCR was repeated three times with three replicates.

Western blot analysis. Following culture of BMMs with M-CSF (30 ng/ml) and RANKL (100 ng/ml) in the presence or absence of PEE, cells were washed with cold PBS and lysed in $100 \mu 1$ of radioimmunoprecipitation assay buffer $(25 \mathrm{mM}$ Tris-HCl, pH 7.6, $150 \mathrm{mM} \mathrm{NaCl}, 1 \% \mathrm{NP}-40,1 \%$ sodium deoxycholate, $0.1 \%$ SDS) containing $1 \mathrm{mM}$ phenylmethylsulfonyl fluoride, protease-inhibitor cocktail (Roche Diagnostics $\mathrm{GmbH}$, Mannheim, Germany) and phosphatase inhibitor tablets (Thermo Fisher Scientific, Inc.). Cell lysates were separated by centrifugation at $14,000 \mathrm{x}$ g for $10 \mathrm{~min}$ at $4^{\circ} \mathrm{C}$, then the supernatants were collected for western blot analysis. Total lysates $(30 \mu \mathrm{g})$ were subjected to $10 \%$ SDS-PAGE and then transferred to polyvinylidene fluoride membranes (GE Healthcare Life Sciences). Each membrane was blocked at $4{ }^{\circ} \mathrm{C}$ for $2 \mathrm{~h}$ with 5\% skim milk in TBS with Tween-20 $(50 \mathrm{mM}$ Tris-HCl, pH7.6, $150 \mathrm{mM} \mathrm{NaCl}$ and $0.1 \%$ Tween-20), then incubated with the primary antibodies, described in 'Reagents' $(1: 1,000)$ at $4^{\circ} \mathrm{C}$ overnight. Horseradish peroxidase-conjugated immunoglobulin G (1:5,000; nos. sc2004 and sc2005; Santa Cruz Biotechnology, Dallas, TX, USA) as a secondary antibody, incubated for $1 \mathrm{~h}$ at room temperature. Immunoreactive proteins were detected using an enhanced chemiluminescence detection system (Thermo Fisher Scientific, Inc.), according to the manufacturer's protocols.

$\left[\mathrm{Ca}^{2+}\right]_{i}$ measurement. $\left[\mathrm{Ca}^{2+}\right]_{\mathrm{i}}$ was determined with the $\mathrm{Ca}^{2+-}$ sensitive fluorescence dye Fura2-acetoxymethyl ester (Fura2-AM, TEFLabs Inc, Austin, TX, USA), as described previously (11). Briefly, isolated BMMs were plated on cover glass when they had reached $\sim 80 \%$ confluence $\left(6 \times 10^{5}\right.$ cells/35-mm dish) the day before the experiment. Cells were loaded with Fura2-AM for $50 \mathrm{~min}$. Then, the cover glass containing cells was transferred to a perfusion chamber and perfused with 4-(2-hydroxyethyl)-1-piperazineethanesulfonic acid (HEPES) buffer (10 mmol/l HEPES, $140 \mathrm{mmol} / \mathrm{l} \mathrm{NaCl}$, $5 \mathrm{mmol} / 1 \mathrm{KCl}, 1 \mathrm{mmol} / 1 \mathrm{MgCl}_{2}, 1 \mathrm{mmol} / 1 \mathrm{CaCl}_{2}$ and $10 \mathrm{mmol} / \mathrm{l}$ glucose, adjusted to $\mathrm{pH} 7.4$ and $310 \mathrm{mOsm})$. Cells were briefly washed with HEPES buffer and continuously perfused with HEPES buffer. Each of the indicated compounds were diluted in HEPES buffer and perfused for a designated time. Under continuous perfusion with HEPES buffer, intracellular fluorescence was excited at dual wavelengths (340 and $380 \mathrm{~nm}$ ) and the emitted fluorescence $(510 \mathrm{~nm})$ was captured using a charge coupled device camera (Andor Technology Ltd, Belfast, UK). Captured images were digitized and analyzed using MetaFluor software (version 7.8.3.0; Molecular Devices, Inc., Downington, PA, USA), with data expressed as the ratio of fluorescence intensities (F340/F380). Indicated chemical compound (PEE, nicardipine, and U73122) was respectively diluted in the HEPES buffer and then perfused on cells for the designated time. To remove extracellular $\mathrm{Ca}^{2+}$ ions, $\mathrm{CaCl}_{2}$ in HEPES buffer was replaced with same concentration of ethylene glycol-bis ( $\beta$-aminoethyl ether)-N,N,N',N'-tetraacetic acid (EGTA; Sigma Aldrich; Merck KGaA) and presented as ' $\mathrm{Ca}^{2+}$-free'.

Statistical analysis. Data are presented as the mean \pm standard deviation of results from at least three independent experiments. Statistical differences were analyzed using one-way analysis of variance followed by Tukey's post hoc test. SPSS 14.0 software (SPSS Inc., Chicago, IL, USA) was used to analyze results and $\mathrm{P}<0.05$ was considered to indicate a statistically significant difference.

\section{Results}

PEE reduces $R A N K L$-mediated TRAP $P^{+}$MNC formation in a dose-dependent manner. As indicated in previous studies, $\left[\mathrm{Ca}^{2+}\right]_{\mathrm{i}}$ mobilization stimulated by RANKL is a key factor for triggering the final stage of differentiation of osteoclasts $(9,10,15)$. Considering that it has been previously demonstrated that the constituents of PJ caused antagonistic effects on acetylcholine- and histamine-induced $\left[\mathrm{Ca}^{2+}\right]_{\mathrm{i}}$ increase in isolated guinea pig ileum (3), it was proposed by the current authors that PJ may affect osteoclastogenesis by regulating $\left[\mathrm{Ca}^{2+}\right]_{\mathrm{i}}$ mobilization.

Firstly, the cytotoxicity of PEE on BMMs was evaluated. BMMs were treated with PEE in a dose- and time-dependent manner and cell viability was assessed. PEE treatment did not exert a cytotoxic effect on BMMs regardless of the concentration of PEE or incubation duration (Fig. 1A and B). Subsequently, the effect of PEE on RANKL-mediated TRAP ${ }^{+}$MNC formation was evaluated using a standard in vitro osteoclast culture method. Isolated BMMs were simultaneously treated with RANKL and various concentrations of PEE $(0,5,10,25$ and $50 \mu \mathrm{g} / \mathrm{ml}$ ), and were incubated for 4 days. Following incubation for $0,1,2,3$ and 4 days, $\mathrm{TRAP}^{+} \mathrm{MNC}$ formation and total TRAP activity were measured in cells (Fig. 1C). Compared with the control, the number of $\mathrm{TRAP}^{+} \mathrm{MNCs}$ was significantly reduced following PEE treatment in a dose-dependent manner $(\mathrm{P}<0.05$ for 5 and $10 \mu \mathrm{g} / \mathrm{ml} \mathrm{PEE}, \mathrm{P}<0.01$ for 25 and $50 \mu \mathrm{g} / \mathrm{ml}$ PEE; Fig. 1D). Marked reduction of TRAP activity in PEE-treated cells was also observed (Fig. 1E). These results suggest that PEE negatively regulates RANKL-mediated 
A

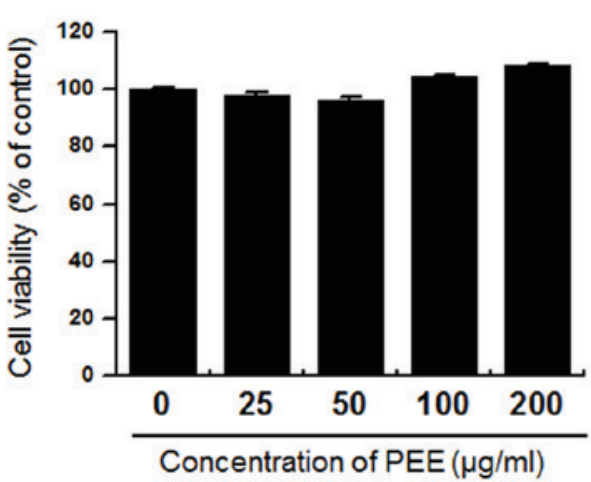

B

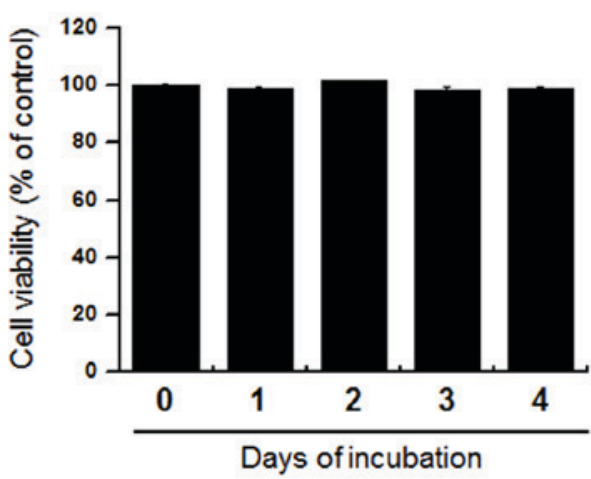

C Concentration of PEE $(\mu \mathrm{g} / \mathrm{ml})$

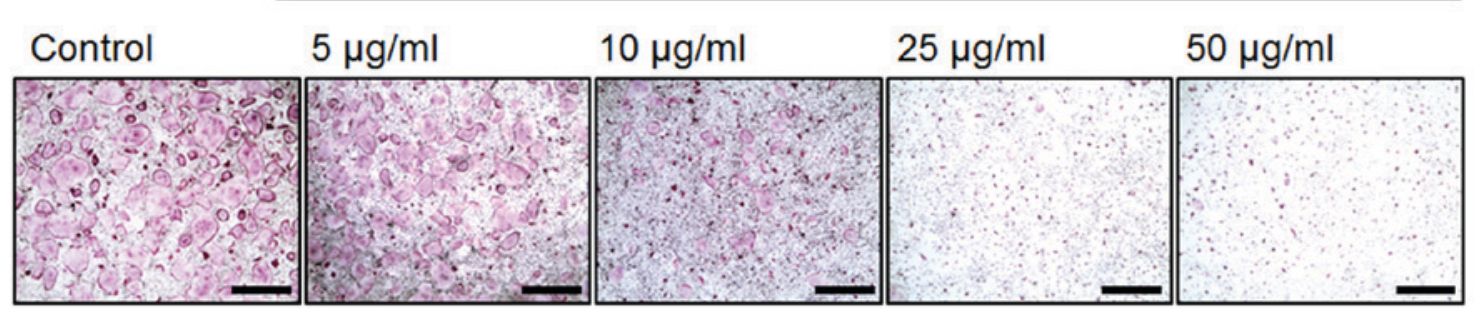

D

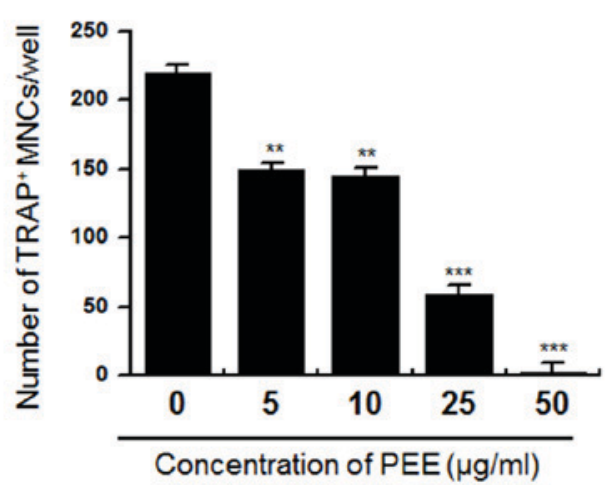

E

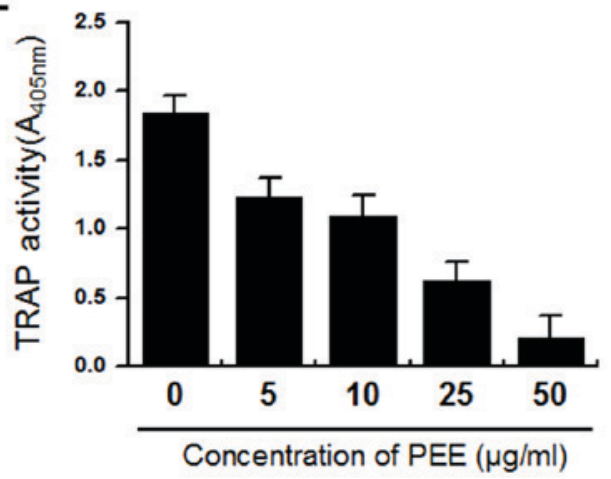

Figure 1. Effect of PEE on the viability of BMMs and TRAP ${ }^{+}$MNC formation. Isolated BMMs were treated with PEE in a dose- and time-dependent manner. (A) Cells were treated with various concentrations of PEE $(0,25,50,100$ and $200 \mu \mathrm{g} / \mathrm{ml})$ and incubated for $4 \mathrm{days}$. (B) Cells were treated with $25 \mu \mathrm{g} / \mathrm{ml} \mathrm{PEE}$ and incubated for various durations $(0,1,2,3$ and 4 days). (C) Intracellular TRAP was stained to evaluate the effect of PEE on osteoclastogenesis. TRAP staining of osteoclasts was conducted following 4 days culture in the presence of $0,5,10,25$ and $50 \mu \mathrm{g} / \mathrm{ml}$ PEE. Scale bar, $200 \mu \mathrm{m}$, at $\mathrm{x} 10 \mathrm{magnification}$. (D) Quantification of osteogenesis. TRAP ${ }^{+}$MNCs with $>3$ nuclei were classed as mature osteoclasts. (E) TRAP activity was measured with a TRAP solution assay at day 4. Absorbance was measured at $405 \mathrm{~nm}$. Data are presented as the mean \pm standard deviation and are representative of at least three experiments. ${ }^{* *} \mathrm{P}<0.05,{ }^{* * *} \mathrm{P}<0.01$ vs. $0 \mu \mathrm{g}$ PEE. PEE, Peucedanum japonicum Thunb. ethanol extract; BMM, bone marrow-derived macrophage; TRAP, tartrate resistant acid phosphatase; MNC, multinuclear cell.

osteoclastogenesis in a dose-dependent manner without inducing cytotoxicity.

Suppression of differentiation-related gene expression by PEE. TRAP, Oscar, Ctsk, TM7SF4, ATP6V0D2 and NFATC1 are known to be differentiation-related marker genes that are crucial for cell motility, fusion and bone resorption (4,16-20). To determine whether PEE regulates differentiation at the gene level, RANKL-stimulated BMMs were treated with PEE and incubated for $0,1,2,3$ or 4 days prior to RT-qPCR. The level of endogenous expression of the differentiation-related marker genes was subsequently evaluated. The results indicated that treatment of PEE on RANKL-stimulated BMMs markedly inhibited RANKL-mediated mRNA expression of marker genes including TRAP, Oscar, Ctsk, TM7SF4, ATP6V0D2 and NFATc1, compared with RANKL-only treated BMMs (Fig. 2). This indicates that PEE affects and modifies the differentiation-mediating signaling pathway in the early stages of osteoclastogenesis.

PEE elicits a transient $\left[\mathrm{Ca}^{2+}\right]_{i}$ increase, which is dependent on both extracellular and intracellular $\mathrm{Ca}^{2+}$ mobilization. To further investigate the molecular mechanisms underlying the alteration of osteoclastogenesis caused by PEE, the intracellular $\mathrm{Ca}^{2+}$ responses to PEE were evaluated. Isolated BMMs plated on the cover glass were loaded with Fura2-AM, a fluorescent indicator of free $\mathrm{Ca}^{2+}$. Acute treatment of PEE on BMMs elicited a transient $\left[\mathrm{Ca}^{2+}\right]_{\mathrm{i}}$ increase, whereas removal of extracellular $\mathrm{Ca}^{2+}$ reversed this effect (Fig. 3A). To characterize PEE-induced $\left[\mathrm{Ca}^{2+}\right]_{\mathrm{i}}$ mobilization, cells were pretreated with nicardipine and U73122, which are inhibitors 

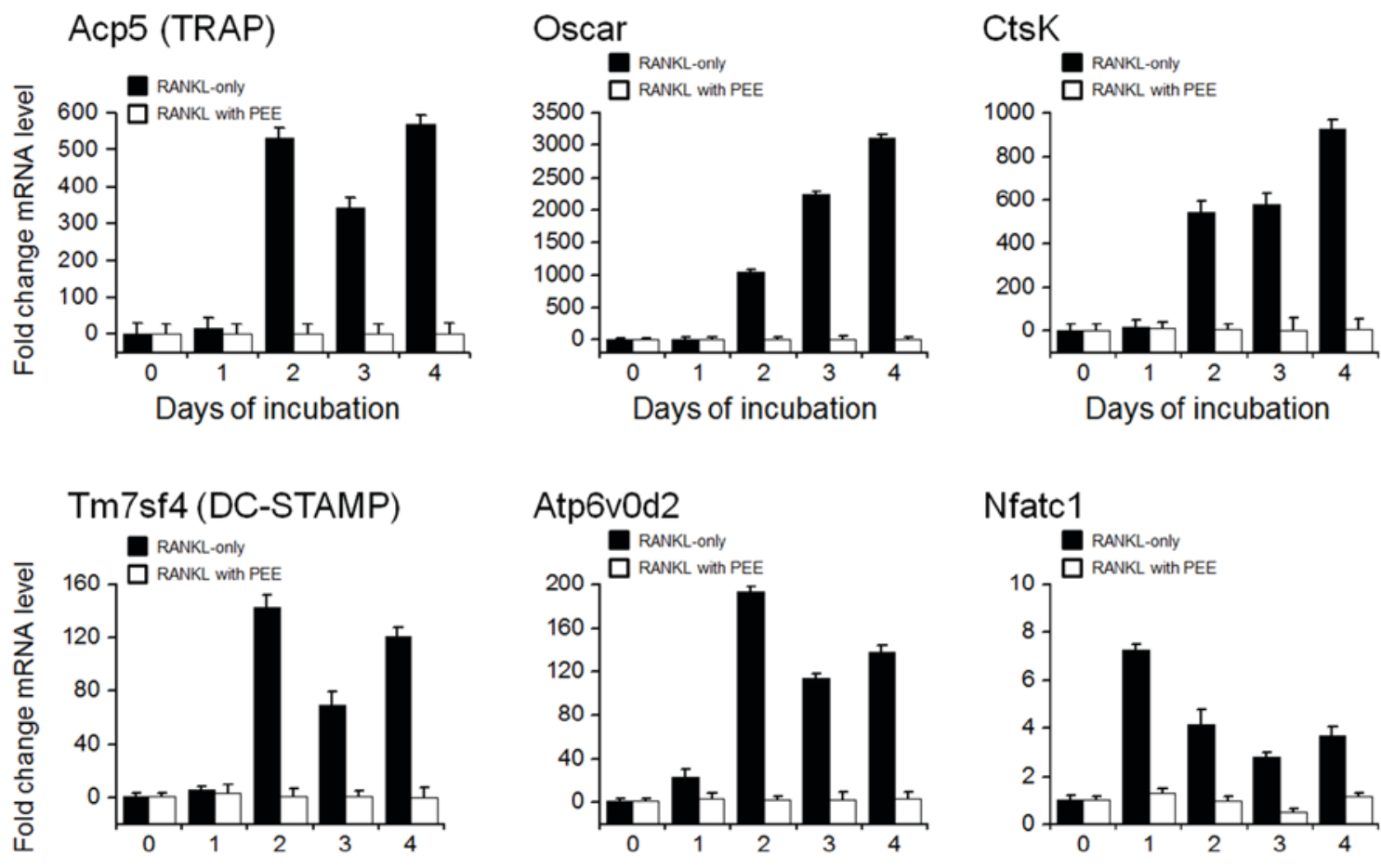

Days of incubation

Days of incubation

Days of incubation

Figure 2. Expression of osteoclast differentiation marker genes. Bone marrow-derived macrophages were cultured with or without $25 \mu \mathrm{g} / \mathrm{ml} \mathrm{PEE}$ for $0,1,2,3$ or 4 days. Reverse transcription-quantitative polymerase chain reaction assays were performed to evaluate the expression levels of osteoclast differentiation marker genes, ACP5 (TRAP), Oscar, CtsK, TM7SF4 (DC-STAMP), ATP6V0D2 and NFATC1. The expression values represent three biological replicates and are presented relative to the GAPDH expression in each sample. PEE, Peucedanum japonicum Thunb. ethanol extract; TRAP, tartrate resistant acid phosphatase; CtsK, cathepsin K; DC-STAMP, dendrocyte expressed seven transmembrane protein; nuclear factor of activated T cells, cytoplasmic 1; ATP6V0D2, ATPase $\mathrm{H}^{+}$Transporting V0 Subunit D2.

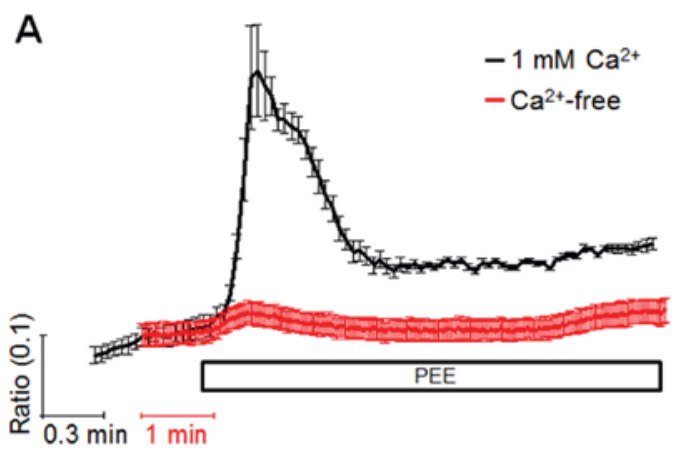

C

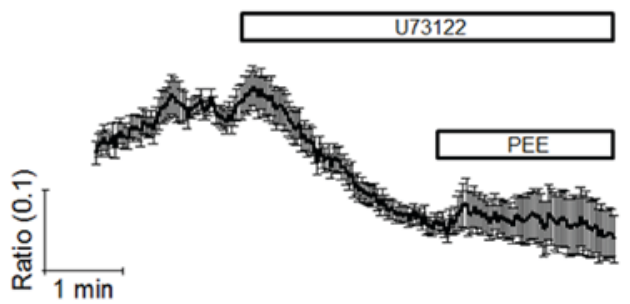

B

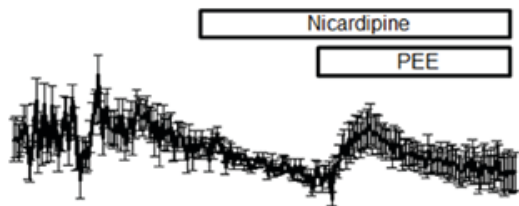

$\longdiv { \mathrm { min } }$

D

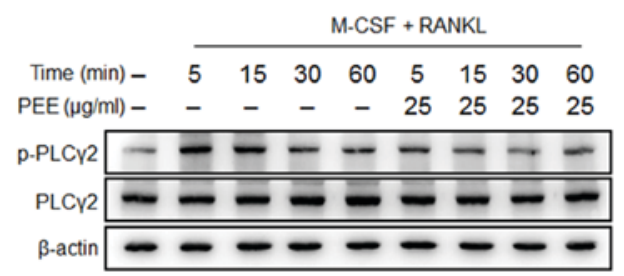

Figure 3. Characterization of PEE-mediated $\mathrm{Ca}^{2+}$ responses. Isolated bone marrow-derived macrophages were seeded and cultured for $24 \mathrm{~h}$ in the presence of M-CSF, and $\left[\mathrm{Ca}^{2+}\right]_{\text {i }}$ mobilization was measured using Fura2 dye on the following day. Cells were initially perfused with HEPES buffer, and (A-C) each designated compound, including PEE, nicardipine $(10 \mu \mathrm{M})$ and U73122 $(10 \mu \mathrm{M})$, was used to treat cells for the indicated time. To chelate extracellular Ca ${ }^{2+}$ ions, $\mathrm{CaCl}_{2}$ in HEPES buffer was replaced with same concentration of EGTA and presented as $\mathrm{Ca}^{2+}$ free. Each trace indicates the mean value \pm standard deviation from three or more independent experiments. (D) The effect of PEE on PLC $\gamma 2$ activation was evaluated using western blot analysis. Cells were cultured under the indicated conditions, and whole cell lysate was used for detecting PLC $\gamma 2$ activation. The total PLC $\gamma 2$ was also evaluated and used as a loading control. PEE, Peucedanum japonicum Thunb. ethanol extract; RANKL, receptor activator of nuclear factor $\mathrm{\kappa B}$ ligand; M-CSF, macrophage colony-stimulating factor; PLC $\gamma 2$, phospholipase C $\gamma 2$; EGTA, ethylene glycol-bis ( $\beta$-aminoethyl ether)-N,N,N',N'-tetraacetic acid. 
A

\begin{tabular}{|c|c|c|c|c|c|c|c|c|c|}
\hline A & & & & & & $+R A$ & & & \\
\hline Time (day) & 0 & 1 & 2 & 3 & 4 & 1 & 2 & 3 & 4 \\
\hline PEE ( $\mu \mathrm{g} / \mathrm{ml})$ & - & - & - & - & - & 25 & 25 & 25 & 25 \\
\hline p-CREB & 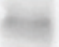 & $=$ & - & 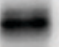 & 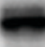 & 50 & +1 & -4 & \\
\hline
\end{tabular}

\section{B}

\begin{tabular}{|c|c|c|c|c|c|c|c|c|c|}
\hline \multirow[b]{2}{*}{ Time (day) } & \multirow[b]{2}{*}{0} & \\
\hline & & 1 & 2 & 3 & 4 & 1 & 2 & 3 & 4 \\
\hline $\mathrm{PEE}(\mu \mathrm{g} / \mathrm{ml})$ & - & - & - & - & - & 25 & 25 & 25 & 25 \\
\hline NFATc1 & & & & & & & . & & \\
\hline$\beta$-actin & & & & & & & & & \\
\hline
\end{tabular}

C

\begin{tabular}{|c|c|c|c|c|c|c|c|}
\hline \multirow[b]{2}{*}{ Time (h) } & \multirow[b]{2}{*}{0} & \\
\hline & & 6 & 12 & 24 & 6 & 12 & 24 \\
\hline PEE $(\mu \mathrm{g} / \mathrm{ml})$ & - & - & - & - & 25 & 25 & 25 \\
\hline c-fos & $=0$ & $m$ & 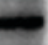 & حas & $=$ & - & $\operatorname{mos}$ \\
\hline$\beta$-actin & andos & & & & & $m$ & $\longrightarrow$ \\
\hline
\end{tabular}

Figure 4. Effects of PEE on RANKL-induced intracellular signaling. Bone marrow-derived macrophages were treated with or without PEE $(25 \mu \mathrm{g} / \mathrm{ml})$ in the presence of RANKL and M-CSF for the indicated durations $(0,1,2,3$ and 4 days). Whole cell extracts were subjected to western blot analysis. (A) Phospho-CREB, (B) NFATc1 and (C) c-fos were detected with the specific antibodies. $\beta$-actin was used as a loading control. PEE, Peucedanum japonicum Thunb. ethanol extract; RANKL, receptor activator of nuclear factor $\kappa \mathrm{B}$ ligand; $\mathrm{M}-\mathrm{CSF}$, macrophage colony-stimulating factor; CREB, cAMP response element-binding protein; NFATc1, nuclear factor of activated T cells, cytoplasmic 1 .

of VGCCs and PLC, respectively. The inhibition of VGCCs and PLC resulted in the suppression of PEE-induced $\left[\mathrm{Ca}^{2+}\right]$ ${ }_{i}$ increase (Fig. 3B and C). Additionally, PLC phosphorylation in response to RANKL stimulation was reduced by PEE treatment in a dose-dependent manner (Fig. 3D). These results suggest that PEE treatment of BMMs causes $\left[\mathrm{Ca}^{2+}\right]_{\mathrm{i}}$ mobilization that is dependent on extracellular and intracellular $\mathrm{Ca}^{2+}$ stores.

PEE treatment of BMMs suppresses NFATcl activity by regulating $C R E B$ activity. $\mathrm{CREB}$, together with $\left[\mathrm{Ca}^{2+}\right]_{\mathrm{i}}$ mobilization, is essential in the regulation of RANKL-mediated NFATc1 activity (21). Thus, $\mathrm{Ca}^{2+}$-CREB-mediated NFATc1 activation induces expression of numerous genes, including NFATc1 itself, c-fos and TRAP (4). The current study evaluated whether PEE affects RANKL-mediated CREB activation and NFATc1 and c-fos expression. RANKL-stimulated BMMs were treated with PEE and incubated for $0,1,2,3$ or 4 days. Following incubation, total cell lysates were collected and subjected to western blot analysis. It was determined that PEE treatment sequentially suppressed RANKL-elicited CREB phosphorylation (Fig. 4A) and inhibited the induction of NFATc1 and c-fos expression (Fig. 4B and C). Notably, phosphorylation of CREB in PEE-treated sample was observed to increase at day 4 compared with the RANKL-only treated sample. At this point, further studies are required to elucidate how PEE enhances the phosphorylation of CREB at day 4. These results demonstrate that PEE strongly inhibits RANKL-mediated osteoclastogenesis via disruption of the CREB-NFATc1 signaling pathway.

\section{Discussion}

Natural extracts have been extensively evaluated in drug discovery and development owing to their potential therapeutic benefits. The crude extracts derived from natural products generally possess components with diverse bioactivities (22). The components from crude extracts interact with intracellular molecules and alter cellular responses (23). Notably, it has been reported that the compounds from PJ exhibit anti-oxidant and anti-inflammatory properties $(1,3)$, which are important biological properties for modulating bone remodeling by regulating osteoclast differentiation. Based on this, the current study investigated the physiological roles of PJ on the differentiation of BMMs into osteoclasts.

Previous studies that have investigated crude extracts derived from natural product have reported that they exhibit cytotoxic effects against pathogens $(24,25)$. In the current study, PEE treatment on RANKL-stimulated BMMs suppressed $\mathrm{TRAP}^{+} \mathrm{MNC}$ formation and TRAP activities in a dose- and time-dependent manner. Furthermore, PEE did not exert cytotoxic effects on BMMs up to a concentration of $200 \mu \mathrm{g} / \mathrm{ml}$ and following 4 days of incubation.

Marked suppression of differentiation-related gene expression indicated that PEE may physiologically act on the signaling molecules relaying RANKL-mediated osteoclast differentiation information, resulting in a reduction of osteoclast differentiation. Notably, the expression of the genes TRAP, Oscar, CtsK, DC-STAMP, ATP6V0D2 and NFATC1 were completely suppressed by PEE treatment, indicating that PEE blocks the early events of RANKL-mediated signaling pathways.

RANKL-RANK interactions elicit $\mathrm{Ca}^{2+}$ responses in the early stages of differentiation (4). RANKL-induced $\mathrm{Ca}^{2+}$ responses are dependent on the $\mathrm{Ca}^{2+}$ influx from both internal and external $\mathrm{Ca}^{2+}$ stores (26). The lack of $\mathrm{Ca}^{2+}$ influx from either store results in the reduction of osteoclastogenesis. Furthermore, it has previously been reported that extracts of $G$. hederacea to cause transient $\mathrm{Ca}^{2+}$ increase via VGCCs, altering RANKL-mediated differentiation of osteoclasts (11). Results from the present study indicate that PEE mobilizes external and internal $\mathrm{Ca}^{2+}$ through VGCCs and inositol 1,4,5-triphosphate production. Previous results have indicated that RANKL-mediated $\mathrm{Ca}^{2+}$ responses are essential in bone homeostasis as they regulate the activities of CREB, c-fos and NFATc1. In addition, the results of the current study suggest that PEE markedly downregulates CREB, NFATc1 and c-fos activity, demonstrating that PEE modulates the RANKL/RANK signaling axis, which primarily regulates osteoclast differentiation. Therefore, PEE modifies RANKL-mediated signal transduction in the early stages of differentiation, leading to a marked reduction of mature osteoclasts.

In conclusion, the results of present study indicate that PEE markedly suppresses RANKL-mediated osteoclastogenesis by disrupting PLC-Ca ${ }^{2+}-\mathrm{CREB} / \mathrm{c}-$ fos-NFATc1 signaling and 
expression of the genes that determine differentiation. Notably, PJ ethanol extract exhibited no cytotoxicity on BMMs even at a high concentration $(\sim 200 \mu \mathrm{g} / \mathrm{ml})$, indicating that PEE physiologically regulates the RANKL-mediated signaling pathway. Collectively, these findings suggest the potential therapeutic use of PJ in treating bone disorders caused by overgrowth of osteoclasts.

\section{Acknowledgements}

The present study was supported by the Basic Science Research Program through the National Research Foundation of Korea, funded by the Ministry of Education, Science and Technology (grant no. 2011-0030130, NRF-2015R1D1A1A01058272).

\section{References}

1. HisamotoM,KikuzakiH,OhigashiHandNakataniN: Antioxidant compounds from the leaves of Peucedanum japonicum Thunb. J Agric Food Chem 51: 5255-5261, 2003.

2. Nukitrangsan $\mathrm{N}$, Okabe T, Toda T, Inafuku M, Iwasaki $\mathrm{H}$ and Oku H: Effect of Peucedanum japonicum Thunb extract on high-fat diet-induced obesity and gene expression in mice. J Oleo Sci 61: 89-101, 2012.

3. Aida Y, Kasama T, Takeuchi N, Chiba M and Tobinaga S: Pharmacological activities of khellactones, compounds isolated from Peucedanum japonicum THUNB. and Peucedanum praeruptorium DUNN. Methods Find Exp Clin Pharmacol 20: 343-351, 1998.

4. Takayanagi H, Kim S, Koga T, Nishina H, Isshiki M, Yoshida H, Saiura A, Isobe M, Yokochi T, Inoue J, et al: Induction and activation of the transcription factor NFATc1 (NFAT2) integrate RANKL signaling in terminal differentiation of osteoclasts. Dev Cell 3: 889-901, 2002.

5. Kim H, Kim T, Jeong BC, Cho IT, Han D, Takegahara N, Negishi-Koga T, Takayanagi H, Lee JH, Sul JY, et al: Tmem64 modulates calcium signaling during RANKL-mediated osteoclast differentiation. Cell Metab 17: 249-260, 2013.

6. Takayanagi H, Ogasawara K, Hida S, Chiba T, Murata S, Sato K, Takaoka A, Yokochi T, Oda H, Tanaka K, et al: T-cell-mediated regulation of osteoclastogenesis by signalling cross-talk between RANKL and IFN-gamma. Nature 408: 600-605, 2000.

7. Yang YM, Jung HH, Lee SJ, Choi HJ, Kim MS and Shin DM: TRPM7 is essential for RANKL-induced osteoclastogenesis. Korean J Physiol Pharmacol 17: 65-71, 2013.

8. Son A, Kim MS, Jo H, Byun HM and Shin DM: Effects of Inositol 1,4,5-triphosphate on osteoclast differentiation in RANKL-induced osteoclastogenesis. Korean J Physiol Pharmacol 16: 31-36, 2012.

9. Yang YM, Kim MS, Son A, Hong JH, Kim KH, Seo JT, Lee SI and Shin DM: Alteration of RANKL-induced osteoclastogenesis in primary cultured osteoclasts from SERCA2 $2^{+/-}$mice. J Bone Miner Res 24: 1763-1769, 2009.

10. Kim HJ, Prasad V, Hyung SW, Lee ZH, Lee SW, Bhargava A, Pearce D, Lee Y and Kim HH: Plasma membrane calcium ATPase regulates bone mass by fine-tuning osteoclast differentiation and survival. J Cell Biol 199: 1145-1158, 2012.
11. Hwang JK, Erkhembaatar M, Gu DR, Lee SH, Lee CH, Shin DM, Lee YR and Kim MS: Glechoma hederacea suppresses RANKL-mediated osteoclastogenesis. J Dent Res 93: 685-690, 2014.

12. Lee JW, Roh TC, Rho MC, Kim YK and Lee HS: Mechanisms of relaxant action of a pyranocoumarin from Peucedanum japonicum in isolated rat thoracic aorta. Planta Med 68: 891-895, 2002.

13. Lee SH, Kim T, Jeong D, Kim N and Choi Y: The Tec family tyrosine kinase Btk Regulates RANKL-induced osteoclast maturation. J Biol Chem 283: 11526-11534, 2008.

14. Livak KJ and Schmittgen TD: Analysis of relative gene expression data using real-time quantitative PCR and the 2(-Delta Delta C(T)) Method. Methods 25: 402-408, 2001.

15. Koga T, Inui M, Inoue K, Kim S, Suematsu A, Kobayashi E, Iwata T, Ohnishi H, Matozaki T, Kodama T, et al: Costimulatory signals mediated by the ITAM motif cooperate with RANKL for bone homeostasis. Nature 428: 758-763, 2004.

16. Yu M, Moreno JL, Stains JP and Keegan AD: Complex regulation of tartrate-resistant acid phosphatase (TRAP) expression by interleukin 4 (IL-4): IL-4 indirectly suppresses receptor activator of NF-kappaB ligand (RANKL)-mediated TRAP expression but modestly induces its expression directly. J Biol Chem 284: 32968-32979, 2009.

17. Matsumoto M, Kogawa M, Wada S, Takayanagi H, Tsujimoto M, Katayama S, Hisatake K and Nogi Y: Essential role of p38 mitogen-activated protein kinase in cathepsin $\mathrm{K}$ gene expression during osteoclastogenesis through association of NFATc1 and PU.1. J Biol Chem 279: 45969-45979, 2004.

18. Kim K, Lee SH, Ha Kim J, Choi Y and Kim N: NFATc1 induces osteoclast fusion via up-regulation of Atp6v0d2 and the dendritic cell-specific transmembrane protein (DC-STAMP). Mol Endocrinol 22: 176-185, 2008

19. Lee SH, Rho J, Jeong D, Sul JY, Kim T, Kim N, Kang JS, Miyamoto T, Suda T, Lee SK, et al: v-ATPase V0 subunit d2-deficient mice exhibit impaired osteoclast fusion and increased bone formation. Nat Med 12: 1403-1409, 2006.

20. Barrow AD, Raynal N, Andersen TL, Slatter DA, Bihan D, Pugh N, Cella M, Kim T, Rho J, Negishi-Koga T, et al: OSCAR is a collagen receptor that costimulates osteoclastogenesis in DAP12-deficient humans and mice. J Clin Invest 121: 3505-3516, 2011.

21. Sato K, Suematsu A, Nakashima T, Takemoto-Kimura S, Aoki K, Morishita Y, Asahara H, Ohya K, Yamaguchi A, Takai T, et al: Regulation of osteoclast differentiation and function by the CaMK-CREB pathway. Nat Med 12: 1410-1416, 2006.

22. Shen J, Xu X, Cheng F, Liu H, Luo X, Shen J, Chen K, Zhao W, Shen $\mathrm{X}$ and Jiang H: Virtual screening on natural products for discovering active compounds and target information. Curr Med Chem 10: 2327-2342, 2003.

23. McChesney JD: Natural products in drug discovery-organizing for success. P R Health Sci J 21: 91-95, 2002.

24. Nguta JM, Appiah-Opong R, Nyarko AK, Yeboah-Manu D, Addo PG, Otchere I and Kissi-Twum A: Antimycobacterial and cytotoxic activity of selected medicinal plant extracts. J Ethnopharmacol 182: 10-15, 2016.

25. Joray MB, Trucco LD, González ML, Napal GN, Palacios SM, Bocco JL and Carpinella MC: Antibacterial and Cytotoxic Activity of Compounds Isolated from Flourensia oolepis. Evid Based Complement Alternat Med 2015: 912484, 2015.

26. Kim MS, Yang YM, Son A, Tian YS, Lee SI, Kang SW, Muallem S and Shin DM: RANKL-mediated reactive oxygen species pathway that induces long lasting $\mathrm{Ca}^{2+}$ oscillations essential for osteoclastogenesis. J Biol Chem 285: 6913-6921, 2010. 